\title{
UPAYA PENURUNAN KEJADIAN KEHILANGAN GELAS BERUKURAN SEDANG MELALUI PENERAPAN METODE QUALITY CONTROL CIRCLE (QCC) DI UNIT GIZI, RS ABC, JAKARTA
}

\author{
Jonny \\ Department of Industrial Engineering, Faculty of Engineering, Universitas Bina Nusantara \\ Jln. K. H. Syahdan No. 9 Palmerah Jakarta Barat 11480 \\ jonny@binus.ac.id
}

\begin{abstract}
Nutrition Department of ABC Hospital provides food and beverage for all inpatients based on nutrition standard from their practioners. Therefore, Nutrition Department needs several types of cutlery for serving them food and beverage as needed. The stock of these types of cutlery should be maintained by nutrionists. During August and September 2011, the stock of middle-sized glasses had been deficit. This condition made the Nutrition Department initiate a QCC group named Sushi to prevent the deficit by strengthening the control over the stock. After this improvement, they had successfully suppressed the deficit from 193 to 77 units or $60.10 \%$. Due to hospital regulation that every lost should be redeemed by nutritionist, this improvement had also enable the department to suppreesed the cost of lost units (quality cost).
\end{abstract}

Keyword: Nutritionist, Quality Cost, Quality Control Circle

\begin{abstract}
ABSTRAK
Unit Gizi di RS ABC bertugas menyediakan makanan dan minuman bagi semua pasien rawat inap sesuai dengan standar diet yang ditetapkan oleh dokter yang merawat. Unit Gizi membutuhkan sarana dan prasarana berupa peralatan makan untuk dapat menyajikan makanan dan minuman kepada pasien. Jumlah stok setiap alat makan telah ditetapkan berdasarkan tingkat hunian rumah sakit yang harus selalu dijaga oleh petugas Gizi agar tidak menganggu kelancaran operasional. Selama pengamatan bulan Agustus dan September 2011, terjadi banyak kehilangan untuk gelas berukuran sedang. Untuk itu, beberapa petugas Gizi membentuk tim QCC-Sushi untuk mencegah terjadinya kehilangan tersebut. Setelah dilakukan perbaikan melalui QCC, tim QCC-Sushi mampu menekan jumlah kehilangan gelas berukuran sedang dari 193 menjadi 77 gelas atau sebanyak 60.10\%. Menurut peraturan RS setiap gelas yang hilang harus ditanggung oleh seluruh petugas Unit Gizi. Perbaikan ini berdampak pada menurunnya biaya mutu berupa penurunan kerugian yang harus ditanggung RS akibat kehilangan.
\end{abstract}

Kata kunci: unit gizi, biaya mutu, quality control circle 


\section{PENDAHULUAN}

Pada bulan September 2011, beberapa petugas Gizi membentuk tim QCC untuk menginventaris semua permasalahan yang dihadapi oleh unit Gizi yaitu:

SUSHI01 - cita rasa makanan tidak sesuai standar;

SUSHI02 - alat makan hilang;

SUSHI03 - alat makan tidak bersih.

Dari ketiga masalah yang ada, dikumpulkan data frekuensi kejadian selama bulan Agustus dan September 2011 berdasarkan laporan yang dibuat dan dilaporkan ke manajemen rumah sakit. Dari data tersebut dibuatkan tabel dan grafik sebagai berikut (Tabel 1 dan Gambar 1):

Tabel 1

Frekuensi Kejadian Masalah

\begin{tabular}{c|c|c|c|c|c|c|}
$\begin{array}{c}\text { ID } \\
\text { Masalah }\end{array}$ & $\begin{array}{c}\text { Frekuensi } \\
\text { Kejadian }\end{array}$ & $\begin{array}{c}\text { Frekuensi } \\
\text { Distribusi }\end{array}$ & Keterangan & $\%$ Kejadian & $\%$ Masalah & $\%$ Kumulatif \\
\hline SUSHI02 & 73 & 180 & $\begin{array}{c}6 \text { kali dalam } 30 \\
\text { hari }\end{array}$ & $40,56 \%$ & $78,49 \%$ & $78,49 \%$ \\
\hline SUSHI01 & 11 & 180 & $\begin{array}{c}6 \text { kali dalam } 30 \\
\text { hari }\end{array}$ & $6,11 \%$ & $11,83 \%$ & $90,32 \%$ \\
\hline SUSHI03 & 9 & 180 & $\begin{array}{c}6 \text { kali dalam } 30 \\
\text { hari }\end{array}$ & $5,00 \%$ & $9,68 \%$ & $100,00 \%$ \\
\hline & 93 & & & & $100,00 \%$ & \\
\hline
\end{tabular}

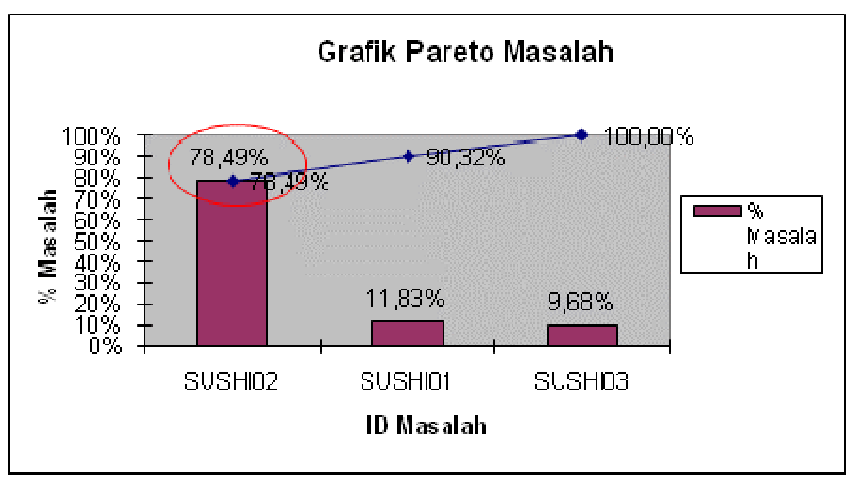

Gambar 1. Grafik pareto masalah.

Dari grafik pareto di atas, diketahui bahwa kejadian alat makan hilang paling sering ditemukan. Adanya kehilangan alat makan ini tentunya berdampak pada QCDSM seperti yang ditunjukkan pada Tabel 2 berikut:

Tabel 2

Aspek QCDSM

\begin{tabular}{l|l|l|l|}
\hline Aspek & Parameter & Indikator Sebelum & Keterangan \\
QUALITY & $\begin{array}{l}\text { Kendali alat } \\
\text { makan. }\end{array}$ & $\begin{array}{l}\text { Sistem kendali } \\
\text { kurang efektif. }\end{array}$ \\
\hline COST & Biaya ganti. & - & $\begin{array}{l}\text { Uang penggantian } \\
\text { bertambah. }\end{array}$ \\
\hline DELIVERY & $\begin{array}{l}\text { Lama antar } \\
\text { makanan. }\end{array}$ & $\begin{array}{l}\text { Ganti dulu baru } \\
\text { antar. }\end{array}$ \\
\hline SAFETY & $\begin{array}{l}\text { Proses } \\
\text { penyembuhan. }\end{array}$ & & $\begin{array}{l}\text { Apabila makanan } \\
\text { terlambat dikirim. }\end{array}$ \\
\hline MORAL & Semangat kerja. & & $\begin{array}{l}\text { Harus mengganti } \\
\text { dengan uang. }\end{array}$ \\
\hline
\end{tabular}


Berdasarkan tabel di atas, tim QCC bertekat untuk: (1) mencari akar penyebab terjadinya alat makan hilang; (2) membuat rencana perbaikan untuk mencegah terjadinya alat makan hilang; (3) mengevaluasi penanggulangan yang telah dilakukan; (4) melakukan standarisasi upaya perbaikan agar dapat mencegah terjadinya alat makan hilang.

\section{METODE}

Penelitian ini dilakukan dengan menggunakan metodologi QCC (Besterfield, 2003) di mana tim QCC-Sushi bertemu secara berkala untuk membahas permasalahan yang dihadapi di unitnya. Dalam metodologi ini, ada delapan langkah dengan siklus Plan-Do-Check-Action sebagai berikut:

Langkah 1: Menentukan Tema; Dalam langkah ini, tim berdiskusi mengenai permasalahan apa saja yang sedang dihadapi oleh unitnya dengan menggunakan metode brainstorming, process mapping, evaluasi QCDSM (quality, cost, delivery, safety, dan moral), dan 5 R (rapi, ringkas, resik, rawat, dan rajin).

Langkah 2: Menentukan Target; Langkah ini dilakukan dengan berpedoman pada kriteria SMART (specific, measurable, achievable, reasonable dan time bound).

Langkah 3: Analisis Kondisi yang Ada; Semua data dan informasi yang dikumpulkan dianalisis dengan berpatokan pada kerangka kerja 4M1E (man, machine, method, material dan environment) dan dampaknya pada aspek QCDSM.

Langkah 4: Analisis Sebab Akibat; Dalam langkah ini, setiap permasalahan harus ditelusuri sampai ditemukannya akar penyebab masalah melalui penggalian 5 Why dan berpatokan pada kaidah uji terbalik. Hal ini dilakukan dengan menggunakan diagram sebab akibat.

Langkah 5: Merencanakan Penanggulangan; Setiap akar penyebab masalah yang ditemukan harus dicarikan penanggulangannya agar tidak terjadi kembali di kemudian hari. Rencana ini dibuat dalam kerangka 5W2H1T (what, why, where, when, who, how, and how much).

Langkah 6: Penanggulangan; Semua rencana yang telah dibuat harus diimplementasikan dan didokumentasikan hasilnya. Apabila ditemukan adanya penyimpangan, tim QCC harus menanggulanginya melalui kerangka kerja PICA (problem identification and corrective action) untuk dicarikan penggulangannya.

Langkah 7: Evaluasi Hasil; Dalam langkah ini, tim QCC harus mengumpulkan hasil dari penanggulangan yang telah dilakukan untuk dibandingkan dengan target untuk melihat apakah tim berhasil menanggulangi permasalahan yang terjadi.

Langkah 8: Standarisasi dan Tindak Lanjut; Dalam standar ini, semua hasil yang memenuhi target harus distandarisasikan supaya tidak terjadi permasalahan yang sama di kemudian hari melalui penetapan atau revisi atas prosedur yang ada.

Delapan langkah ini terangkum pada Gambar 2 berikut: 


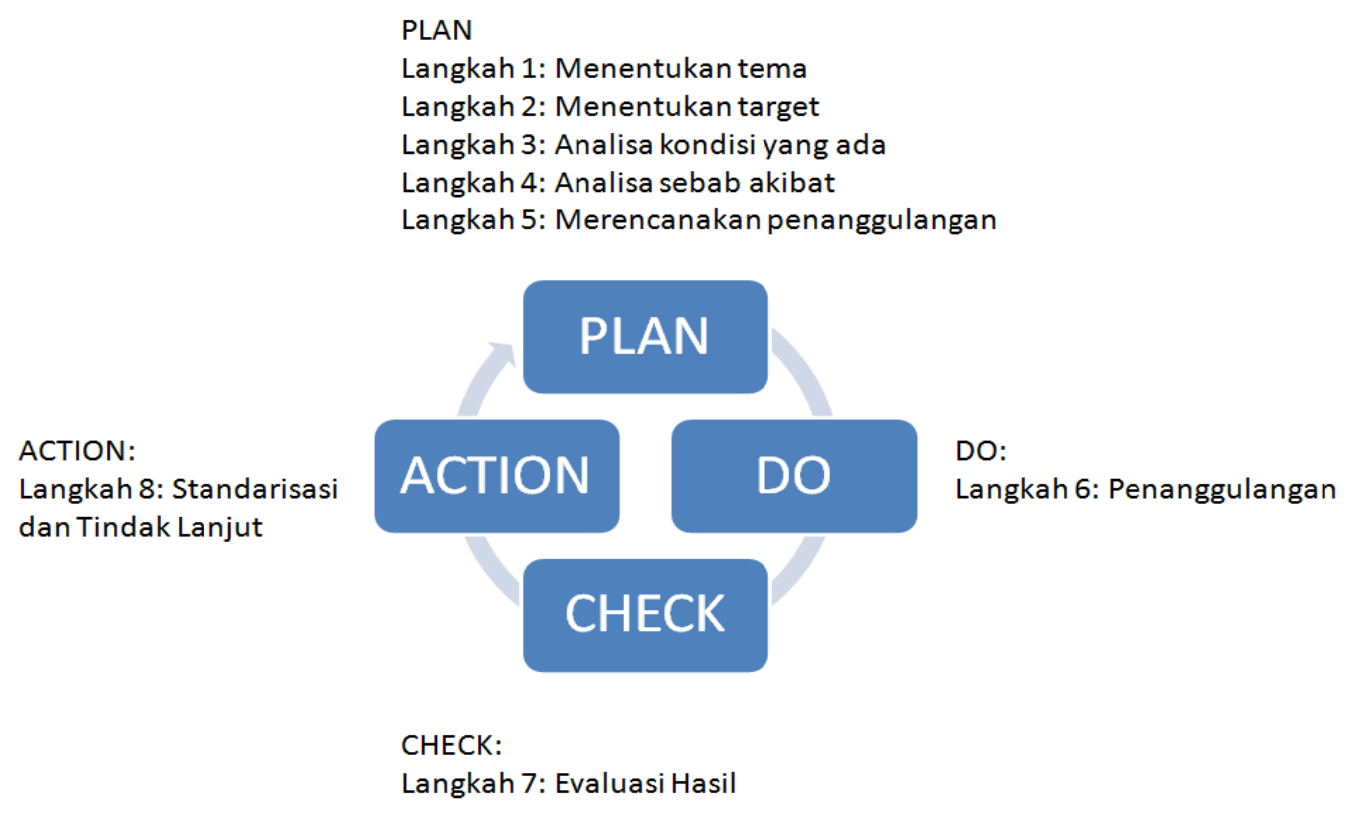

Gambar 2. Delapan langkah QCC.

\section{HASIL DAN PEMBAHASAN}

\section{Langkah 1: Menentukan Tema}

Mengingat besarnya ruang lingkup alat makan yang dimaksud, tim memutuskan untuk mempersempit cakupan alat makan dengan mengambil data jumlah alat makan yang hilang seperti yang ditunjukkan pada Tabel 3 berikut:

Tabel 3

Jumlah alat makan hilang.

\begin{tabular}{r|l|r|r|r|} 
No & Jenis Alat Makan & Agt 11 & Sept 11 & Total \\
\hline 1 & Gelas Sedang & 64 & 129 & 193 \\
\hline 2 & Gelas Panjang & 38 & 78 & 116 \\
\hline 3 & Garpu Makan & 43 & 34 & 77 \\
\hline 4 & Gelas SVIP & 0 & 14 & 14 \\
\hline 5 & Mangkuk Sup Kelas 1 & 0 & 9 & 9 \\
\hline
\end{tabular}

Dari tabel di atas dapat diketahui bahwa gelas sedang merupakan alat makan yang paling banyak hilang. Untuk itu tim QCC menentukan tema: Upaya Penurunan Kejadian Kehilangan Gelas Berukuran Sedang Melalui Penerapan Metode Quality Control Circle (QCC) di Unit Gizi, RS ABC, Jakarta sebagai tema QCC.

\section{Langkah 2: Menentukan Target}

Tim QCC menentukan target perbaikan melalui QCC berdasarkan kaidah SMART yaitu:

Specific : menurunkan jumlah gelas berukuran sedang yang hilang

Measurable : dari 193 per bulan menjadi 96 per bulan (50\%)

Achievable : melalui kerjasama dan komitmen tim 
Reasonable : karena untuk menghilangkan sama sekali perlu waktu agar sistem yang diperbaiki betul-betul berjalan.

Time bound : Dalam waktu 2 bulan

\section{Langkah 3: Analisis kondisi yang ada}

Berikut adalah analisis kondisi yang ada (Tabel 4):

Tabel 4

Analisis Kondisi yang Ada

\begin{tabular}{|c|c|c|c|c|}
\hline FAKTOR & CHECKLIST & STANDAR & AKTUAL & HASIL \\
\hline $\begin{array}{l}\text { Petugas Gizi. } \\
\text { (Man) }\end{array}$ & 1. Pelatihan clear up alat makan. & Harus mengerti. & mengerti. & OK. \\
\hline \multirow[t]{2}{*}{$\begin{array}{l}\text { Cara Clear Up. } \\
\text { (Method) }\end{array}$} & $\begin{array}{l}\text { 2. Kecepatan menangani } \\
\text { kekurangan gelas sedang saat } \\
\text { clear up. }\end{array}$ & Harus cepat. & $\begin{array}{l}\text { Lambat karena } \\
\text { tidak ada alat } \\
\text { kontrol visual. }\end{array}$ & NOT OK. \\
\hline & $\begin{array}{l}\text { 3. Status gelas sedang } \\
\text { yang kurang saat clear up. }\end{array}$ & Harus diketahui. & Tidak diketahui. & NOT OK. \\
\hline $\begin{array}{l}\text { Daftar Inventaris. } \\
\text { (Machine/ Tool) }\end{array}$ & 4. Perincian daftar inventaris. & Harus rinci per area. & Tidak rinci. & NOT OK. \\
\hline $\begin{array}{l}\text { Gelas Sedang. } \\
\text { (Material) }\end{array}$ & $\begin{array}{l}\text { 5. Pengenal gelas untuk petugas } \\
>1 \text { orang. }\end{array}$ & Harus ada marking. & Tidak ada. & NOT OK. \\
\hline $\begin{array}{l}\text { Kondisi ruangan pantry. } \\
\text { (Environment) }\end{array}$ & 6. Keamanan pantry. & $\begin{array}{l}\text { Harus selalu terkunci apabila } \\
\text { tidak ada petugas di dalamnya. }\end{array}$ & $\begin{array}{l}\text { Sudah terkunci saat } \\
\text { tidak ada petugas. }\end{array}$ & OK. \\
\hline
\end{tabular}

Dari tabel di atas dapat dilihat bahwa akar penyebab masalah terjadinya gelas berukuran sedang yang hilang dikarenakan adanya kesulitan dalam melacak keberadaan gelas.

\section{Langkah 4: Analisis Sebab Akibat}

Penyebab kehilangan alat makan dianalisis pada Gambar 3 berikut:

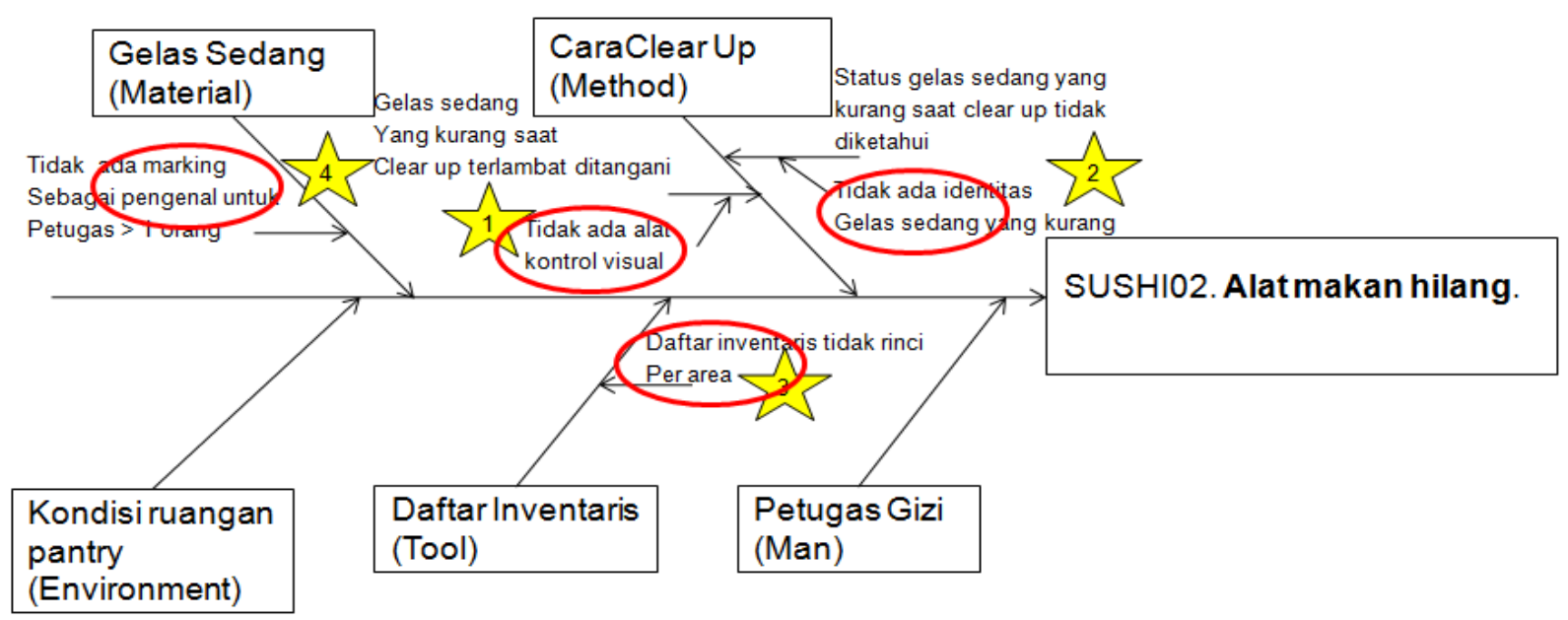

Gambar 3. Diagram sebab akibat.

Dari diagram sebab akibat di atas, dapat kita ketahui bahwa ada empat akar penyebab hilangnya gelas berukuran sedang, antara lain karena: (1) daftar inventaris tidak dibagi per area; (2) 
tidak ada alat kontrol visual sehingga penanganan terlambat; (3) gelas sedang dengan $>2$ orang PJ tidak dipisahkan dengan marking; (4) gelas yang kurang tidak diketahui statusnya.

\section{Langkah 5: Merencanakan Penanggulangan}

Beberapa rencana penanggulangan yang dibuat untuk mengatasi kehilangan gelas dimuat pada tabel 5 berikut:

Tabel 5

Rencana Penanggulangan

\begin{tabular}{|c|c|c|c|c|}
\hline Akar Penyebab & Solusi & Aktivitas & PIC & Due Date \\
\hline 1. Tidak ada alat kontrol visual. & $\begin{array}{l}\text { 1. Gunakan krat gelas sedang } \\
\text { sebagai alat kontrol visual. }\end{array}$ & $\begin{array}{l}\text { 1. Melakukan revisi instruksi } \\
\text { kerja. }\end{array}$ & Petuas A & Oktober 2011 \\
\hline $\begin{array}{l}\text { 2. Tidak ada identitas gelas sedang } \\
\text { yang kurang. }\end{array}$ & $\begin{array}{l}\text { 2. Buatkan kartu tinggal } \\
\text { sebagai status gelas sedang } \\
\text { yang kurang. }\end{array}$ & $\begin{array}{l}\text { 2. Buat rincian daftar inventaris } \\
\text { per area. }\end{array}$ & Petuas B & Oktober 2011 \\
\hline $\begin{array}{l}\text { 3. Daftar inventaris tidak rinci per } \\
\text { area. }\end{array}$ & $\begin{array}{l}\text { 3. Rinci daftar inventaris per } \\
\text { areanya. }\end{array}$ & $\begin{array}{l}\text { 3. Buat kartu tinggal sebagai } \\
\text { status gelas sedang yang kurang. }\end{array}$ & Petuas C & Oktober 2011 \\
\hline \multirow[t]{3}{*}{$\begin{array}{l}\text { 4. Tidak ada marking sebagai } \\
\text { pengenal untuk petugas }>1 \text { orang. }\end{array}$} & \multirow{3}{*}{$\begin{array}{l}\text { 4. Buat marking pada gelas } \\
\text { sedang sebagai pengenal } \\
\text { untuk petugas }>1 \text { orang yaitu } \\
\text { di pantry } 3 \text {. }\end{array}$} & $\begin{array}{l}\text { 4. Buat marking gelas sedang di } \\
\text { pantry } 3 \text {. }\end{array}$ & Petuas D & Oktober 2011 \\
\hline & & $\begin{array}{l}\text { 5. Sosialisasi hasil revisi instruksi } \\
\text { kerja. }\end{array}$ & Petuas E & Oktober 2011 \\
\hline & & $\begin{array}{l}\text { 6. Menerapkan instruksi kerja } \\
\text { hasil revisi. }\end{array}$ & Semua Petugas Gizi & Oktober 2011 \\
\hline
\end{tabular}

\section{Langkah 6: Penanggulangan}

Berikut ini adalah beberapa aktifitas penanggulangan yang dilakukan. Penanggulangan 1: revisi instruksi kerja (Tabel 6, Gambar 4).

Tabel 6

Revisi Instruksi Kerja

\begin{tabular}{|c|c|c|c|}
\hline Checklist & Bagian & $\begin{array}{l}\text { Sebelum Perbaikan } \\
\text { IK/ GIZI/ } 11 \text { Revisi } 00\end{array}$ & $\begin{array}{l}\text { Sesudah Perbaikan } \\
\text { IK/ GIZI/ 11 Revisi } 01\end{array}$ \\
\hline $\begin{array}{l}\text { 1. Gunakan krat gelas sedang } \\
\text { sebagai alat kontrol visual. }\end{array}$ & Catatan No. 1. & Tidak ada & $\begin{array}{l}\text { Untuk gelas sedang, gunakan krat gelas sedang sebagai alat } \\
\text { kontrol visual dimana semua gelas yang sudah dibersihkan } \\
\text { atau dikumpulkan dari kamar perawatan harus disusun } \\
\text { kembali ke dalam krat gelas sedang dengan rapi. }\end{array}$ \\
\hline \multirow[t]{3}{*}{$\begin{array}{l}\text { 2. Buatkan kartu tinggal sebagai } \\
\text { status gelas sedang yang kurang } \\
\text { dan penanganannya. }\end{array}$} & Pelaksanaan No. 2. & Tidak ada & $\begin{array}{l}\text { Lakukan clear up atas semua alat makan yang telah diantar kan } \\
\text { ke pasien. Apabila pasien masih menggunakan alat makan } \\
\text { tersebut, tuliskan identitasnya pada kartu tinggal. }\end{array}$ \\
\hline & Pelaksanaan No. 5. & Tidak ada & $\begin{array}{l}\text { Hitunglah tempat krat yang kosong. Pastikan jumlahnya } \\
\text { sesuai dengan kartu tinggal yang sudah dibuat. }\end{array}$ \\
\hline & Pelaksanaan No. 6. & Tidak ada & $\begin{array}{l}\text { Serahkan kartu tinggal kepada petugas Gizi shift berikutnya } \\
\text { untuk diclear up. Sebelum shift dimulai. Apabila gelas hilang/ } \\
\text { rusak oleh pasien, laporkan untuk dicharge ke pasien. }\end{array}$ \\
\hline $\begin{array}{l}\text { 3. Rinci daftar inventaris per } \\
\text { areanya. }\end{array}$ & Catatan No. 2. & Tidak ada & $\begin{array}{l}\text { Daftar inventaris alat makan harus dibuatkan secara rinci per } \\
\text { area. }\end{array}$ \\
\hline $\begin{array}{l}\text { 4. Buat marking pada gelas sedang } \\
\text { sebagai pengenal untuk petugas }>1 \\
\text { orang yaitu di pantry } 3 \text {. }\end{array}$ & Catatan No. 3. & Tidak ada & $\begin{array}{l}\text { Perhatikan untuk gelas sedang di pantry 3, bahwa gelas } \\
\text { sedang untuk NSC diberi tanda marking merah dan NSB } \\
\text { diberi tanda marking biru. }\end{array}$ \\
\hline
\end{tabular}



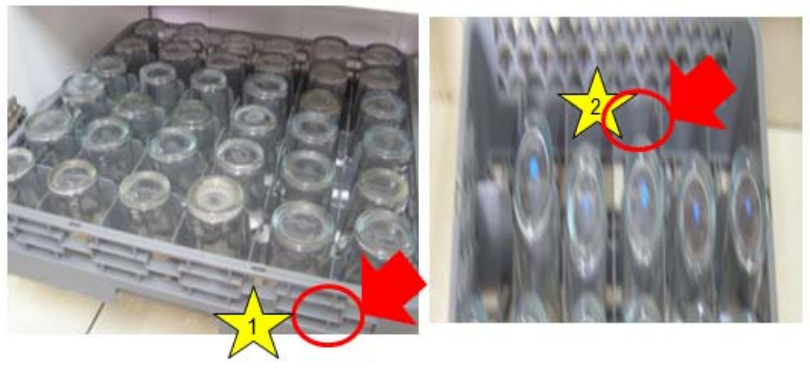

Keterangan:

1. Kratyang awalnya digunakan

mengeringkan gelas sedang,

sekarang dimanfaatkan sebagai

alat kontrolvisual.

2. Petugas Gizi hanya perlu

menghitung tempat kosong dan

memastikan jumlahnya sama dengan

kartu tinggalnya.

Gambar 4.Hasil revisi instruksi kerja.

Penanggulangan 2: daftar inventaris per area pantry (Tabel 7).

Tabel 7

Daftar Inventaris per Area Pantry

\begin{tabular}{|c|c|c|c|c|c|c|c|c|c|c|c|}
\hline No & Nama Alat Makan & Lokasi & Area Distribusi & Marking & Stok Standar & Stok Aktual & Kekurangan & Kartu Tinggal & \begin{tabular}{|l} 
Pecah/ Hilang \\
oleh Pasien
\end{tabular} & \begin{tabular}{|l} 
Pecah/ Hilang \\
oleh Petugas Gizi
\end{tabular} & Keterangan \\
\hline 1 & Gelas Sedang & Pantry 2 & & Tidak Ada & & & & & & & \\
\hline 2 & Gelas Sedang & Pantry 3 & NSB & Biru & & & & & & & \\
\hline 3 & Gelas Sedang & Pantry 3 & NSC & Merah & & & & & & & \\
\hline
\end{tabular}

Penanggulangan 3: kartu tinggal (Gambar 5). Kartu ini memunjukkan lokasi di kamar mana alat makan ditinggal.

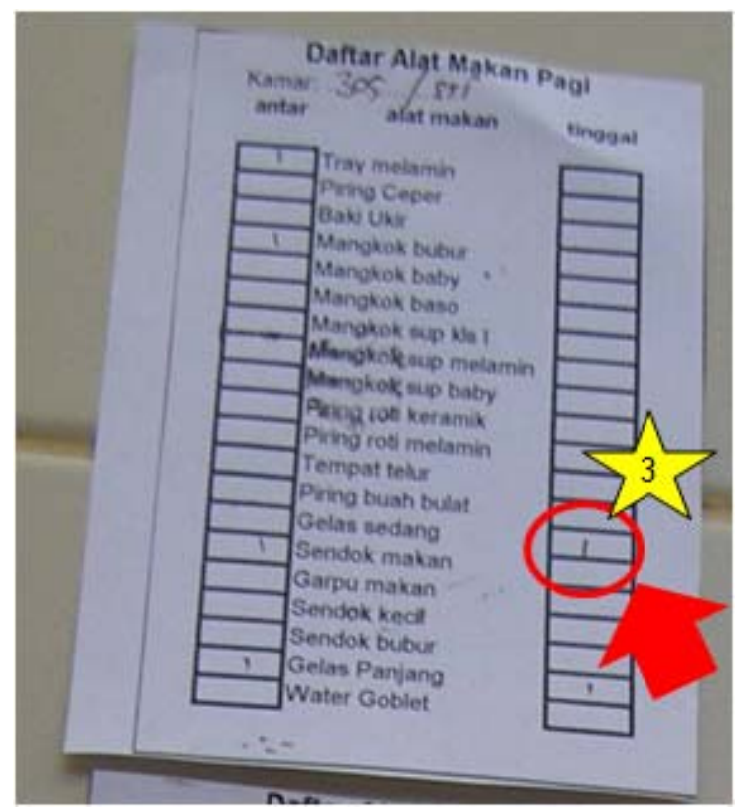

Gambar 5.Kartu tinggal.

Penanggulangan 4: marking (Gambar 6). Marking merah untuk NSC, dan marking biru untuk NSB. 

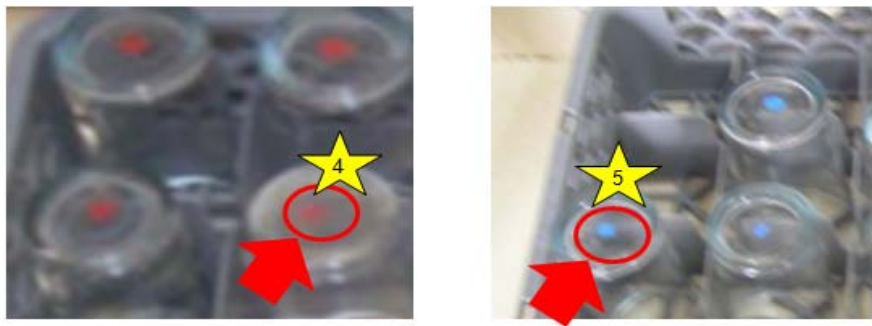

Gambar 6.Marking.

Penanggulangan 5: sosialisasi hasil (Tabel 8).

Tabel 8

Hasil Sosialisasi

\begin{tabular}{|l|l|l|}
\hline Materi Sosialisasi & Isi sosialisasi & Umpan Balik \\
\hline 1. Penerapan instruksi kerja. & $\begin{array}{l}\text { Agar semua petugas Gizi menerapkan } \\
\text { IK/GIZI/11 Revisi 01 dalam proses } \\
\text { clear up alat makan. }\end{array}$ & Petugas Gizi mengerti. \\
\hline 2. Daftar Inventaris. & $\begin{array}{l}\text { Gunakan daftar inventaris yang sudah } \\
\text { dirinci per area. }\end{array}$ & Petugas Gizi mengerti. \\
\hline 3. Kartu tinggal. & $\begin{array}{l}\text { Apabila ada pasien yang masih } \\
\text { menggunakan alat makan saat clear } \\
\text { up, maka buatkan kartu tinggal } \\
\text { sebagai statusnya. }\end{array}$ & Petugas Gizi mengerti. \\
\hline 4. Marking gelas sedang. & $\begin{array}{l}\text { Khusus dipantry 3, gelas sedang NSB } \\
\text { diberi marker biru dan NSC diberi } \\
\text { marker merah. }\end{array}$ & \\
\hline 5. Krat gelas sedang. & $\begin{array}{l}\text { Gunakan krat gelas sedang untuk alat } \\
\text { kontrol stok visual. Jumlah tempat } \\
\text { kosong harus sesuai dengan jumlah } \\
\text { kartu tinggal. }\end{array}$ & Petugas Gizi mengerti \\
\hline
\end{tabular}

Penanggulangan 6: penerapan instruksi kerja hasil sosialisasi (Gambar 7).

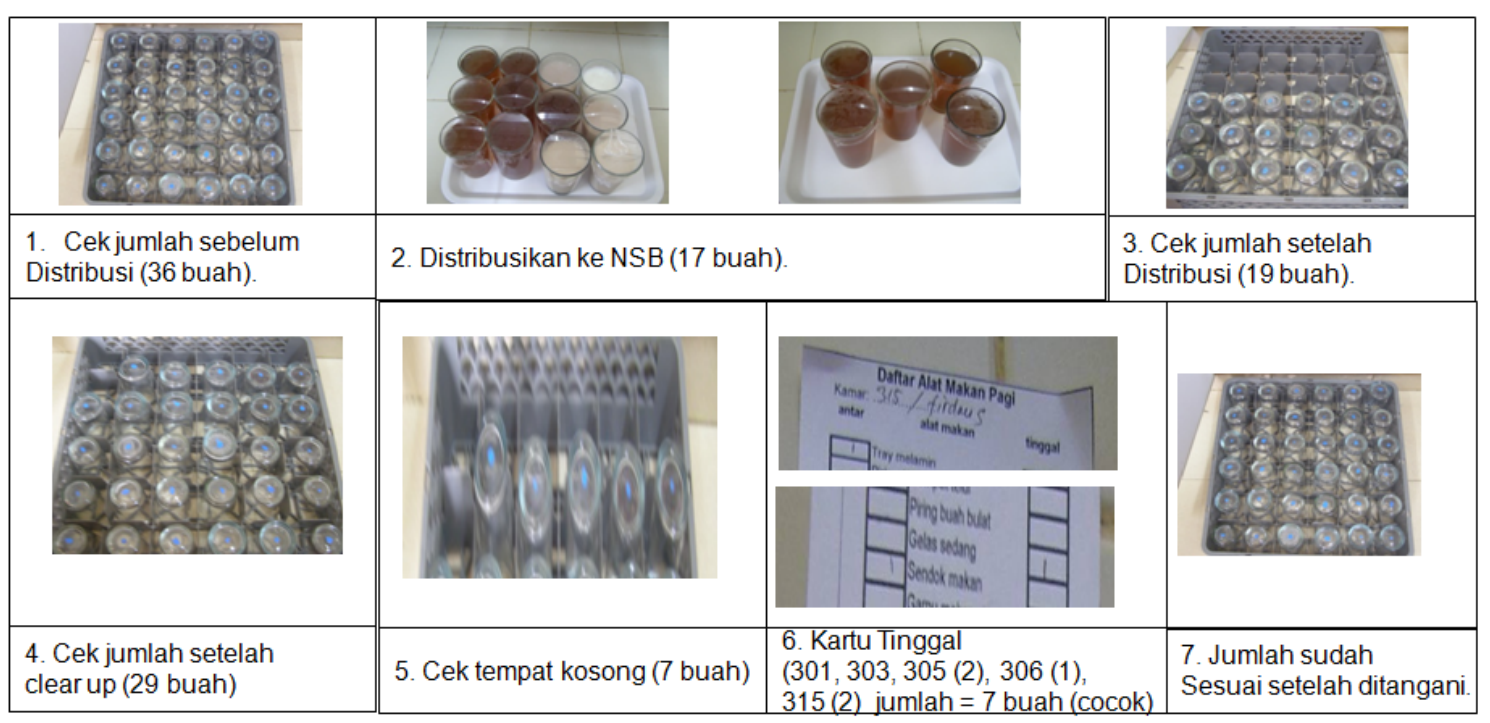

Gambar 7. Hasil implementasi. 
Enam penanggulangan di atas terangkum pada Tabel 9 berikut.

Tabel 9

Daftar Penanggulangan yang Telah Dilakukan

\begin{tabular}{|c|c|c|c|c|c|}
\hline Aktivitas & PIC & Due Date & Hambatan & Tindak Lanjut & Hasil \\
\hline 1. Melakukan revisi instruksi kerja. & Petuas A & Oktober 2011 & Tidak Ada. & $\begin{array}{l}\text { Lanjutkan ke langkah } \\
\text { berikutnya. }\end{array}$ & OK \\
\hline $\begin{array}{l}\text { 2. Buat rincian daftar inventaris per } \\
\text { area. }\end{array}$ & Petuas B & Oktober 2011 & Tidak Ada. & $\begin{array}{l}\text { Lanjutkan ke langkah } \\
\text { berikutnya. }\end{array}$ & OK \\
\hline $\begin{array}{l}\text { 3. Buat kartu tinggal sebagai status } \\
\text { gelas sedang yang kurang. }\end{array}$ & Petuas C & Oktober 2011 & Tidak Ada. & $\begin{array}{l}\text { Lanjutkan ke langkah } \\
\text { berikutnya. }\end{array}$ & OK \\
\hline $\begin{array}{l}\text { 4. Buat marking gelas sedang di } \\
\text { pantry } 3 \text {. }\end{array}$ & Petuas D & Oktober 2011 & Tidak Ada. & $\begin{array}{l}\text { Lanjutkan ke langkah } \\
\text { berikutnya. }\end{array}$ & OK. \\
\hline $\begin{array}{l}\text { 5. Sosialisasi hasil revisi instruksi } \\
\text { kerja. }\end{array}$ & Petuas E & Oktober 2011 & Tidak Ada. & $\begin{array}{l}\text { Lanjutkan ke langkah } \\
\text { berikutnya. }\end{array}$ & OK. \\
\hline $\begin{array}{l}\text { 6. Menerapkan instruksi kerja hasil } \\
\text { revisi. }\end{array}$ & Semua Petugas Gizi & Oktober 2011 & Tidak Ada. & $\begin{array}{l}\text { Lanjutkan ke langkah } \\
\text { berikutnya. }\end{array}$ & OK. \\
\hline
\end{tabular}

Dari tabel di atas, dapat diketahui bahwa semua rencana penanggulangan telah dilaksanakan dan tidak ada hambatan yang ada.

\section{Langkah 7: Evaluasi Hasil}

Setelah perbaikan dilakukan, diketahui bahwa jumlah gelas berukuran sedang yang hilang selama November 2011 adalah 46 gelas dan pada Desember 201131 gelas. Totalnya adalah 77 gelas. Pencapaian ini perlu dibandingkan dengan target yang telah ditetapkan pada langkah 2 sebelumnya (Gambar 8).

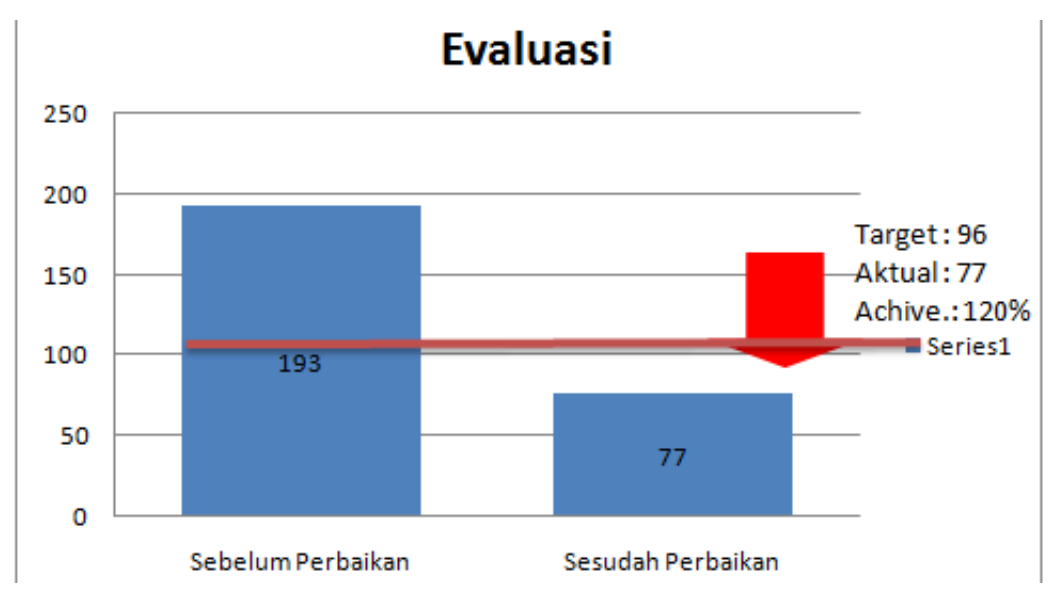

Gambar 8. Evaluasi hasil.

Dari gambar di atas dapat kita ketahui bahwa hasil perbaikan QCC melampaui target dengan pencapaian 120\% sehingga dapat dikatakan bahwa tim QCC berhasil mengurangi kejadian kehilangan alat makan berupa gelas berukuran sedang. Hal ini pun berdampak pada QCDSM dari tim sebagai berikut (Tabel 10): 
Tabel 10

QCDSM Setelah Perbaikan

\begin{tabular}{l|l|l|l|}
\hline Parameter & Indikator Sebelum & Indikator Sesudah & Keterangan \\
\hline Kendali alat makan. & - & & \\
\hline Biaya ganti. & - & & Sistem kendali lebih efektif. \\
\hline Lama antar makanan. & - & & $\begin{array}{l}\text { Kejadian ganti dulu baru antar } \\
\text { berkurang. }\end{array}$ \\
\hline Proses penyembuhan. & - & & $\begin{array}{l}\text { Terlambat kirim makanan } \\
\text { berkurang. }\end{array}$ \\
\hline Semangat kerja. & & $\begin{array}{l}\text { Khawatir mengganti gelas sedang } \\
\text { yang hilang berkurang. }\end{array}$ \\
\hline
\end{tabular}

Menurunnya jumlah gelas sedang yang hilang memberi efek penghematan biaya ganti sebesar Rp464.000. (Tabel 11).

Tabel 11

Biaya Mutu

\begin{tabular}{l|r|r|r|l|} 
Jenis & Sebelum & Sesudah & Selisih & $\%$ \\
\hline Jumlah (Unit) & 193 & 77 & $(116)$ & $-60,10 \%$ \\
\hline Harga / Unit & 4000 & 4000 & & \\
\hline Biaya Mutu & 772.000 & 308.000 & $(464.000)$ & $60,10 \%$ \\
\hline
\end{tabular}

\section{Langkah 8: Standarisasi dan Tindak Lanjut}

Berikut beberapa hal yang perlu dilakukan untuk standarisasi dan tindak lanjut: (1) dalam melakukan clear up, semua petugas Gizi harus mengikuti IK/GIZI/11 inventaris alat dengan menggunakan krat gelas sedang, kartu tinggal, daftar inventaris per area, dan marking; (2) mengajukan kartu tinggal dan daftar inventaris per area sebagai dokumen ISO; (3) mengajukan tema Conim Grup Sushi berikutnya yaitu SUSHI01 - cita rasa makanan tidak sesuai standar.

\section{SIMPULAN}

Berikut adalah kesimpulan yang dapat diambil, yaitu: (1) akar penyebab terjadinya alat makan hilang adalah sulitnya petugas Gizi menelusuri keberadaan alat makan tersebut; (2) rencana perbaikan untuk mencegah terjadinya alat makan hilang meliputi revisi instruksi kerja, daftar inventaris yang lebih dirinci per area, marking dan kartu tinggal; (2) setelah ditanggulangi, kejadian gelas berukuran sedang yang hilang menurun 60\% (dari 193 menjadi 77) dalam 2 bulan; (4) standarisasi terhadap instruksi kerja, daftar inventasi per area, marking dan kartu tinggal dilakukan untuk semua alat makan bukan hanya pada gelas berukuran sedang.

\section{DAFTAR PUSTAKA}

Besterfield, Dale H. (2003). Total Quality Management (3rd edition). New Jersey: Prentice Hall. 